\title{
Microgemma vivaresi (Microsporidia: Tetramicridae): host reaction to xenomas induced in sea scorpions, Taurulus bubalis (Osteichthyes: Cottidae)
}

\author{
Elizabeth U. Canning ${ }^{1}$ and Alan Curry ${ }^{2}$ \\ ${ }^{1}$ Department of Biological Sciences, Imperial College London, Silwood Park Campus, Ascot, Berkshire SL5 7PY, UK; \\ ${ }^{2}$ Health Protection Agency North West, P.O. Box 209, Clinical Sciences Building, Manchester Royal Infirmary, \\ Manchester M13 9WZ, UK
}

Key words: Microsporidia, Microgemma, xenomas, fibroblasts, phagocytes, sea scorpion, liver, muscle

\begin{abstract}
Xenomas caused by Microgemma vivaresi Canning, Feist, Longshaw, Okamura, Anderson, Tsuey Tse et Curry, 2005 were found in liver and skeletal muscle of sea scorpions, Taurulus bubalis (Euphrasen). All muscle xenomas examined were in an advanced stage of destruction. In developing xenomas found in liver, parasites were restricted to the centre of the cell, separated from a parasite-free zone by a nuclear network formed by branching of the host cell nucleus. Although xenomas were able to reach a size of several hundred microns, the surface remained a simple plasma membrane. Host reactions took the form of penetration by phagocytes and isolation by fibroblasts. Once the xenoma had been attacked, the nuclear profiles became pycnotic and the barrier between parasitized and parasite-free zones was lost. Parasite antigens cannot be exposed at the surface of intact xenomas, as the host does not recognise the enlarging cell as foreign. Breaches in the plasma membrane of the xenoma and leakage of parasite antigens are thought to be the stimuli for phagocyte entry into the cell, its isolation by fibroblasts and eventual granuloma formation.
\end{abstract}

The microsporidian genus Microgemma was established by Ralphs and Matthews (1986) for Microgemma hepaticus Ralphs et Matthews, 1986, causing xenoma formation in the liver of grey mullet, Chelon labrosus (Risso). Three further species have been named. Microgemma ovoideum (Thélohan, 1895) transferred from Glugea to Microgemma by Amigó et al. (1996), Microgemma caulleryi (Van den Berghe, 1940) transferred from Glugea by Leiro et al. (1999) and Microgemma vivaresi Canning, Feist, Longshaw, Okamura, Anderson, Tsuey Tse et Curry, 2005. All three induce xenoma formation in liver cells of their respective hosts. Gaidropsarus mediterraneus (L.) (= Motella tricirrata), Cepola macrophthalma L. and Mullus barbatus L. have been named as hosts of $M$. ovoideum (see Amigó et al. 1996) and Hyperoplus lanceolatus (Le Sauvage) as the host of $M$. caulleryi (see Van den Berghe 1940). M. vivaresi infects liver and skeletal muscle of Taurulus bubalis (Euphrasen) (see Canning et al. 2005). Typically, cells containing early stages of parasite development have a simple plasma membrane overlying a region of cytoplasm from which parasites are excluded, within which lies the hypertrophic cell nucleus in the form of a network. Mixed parasitic stages occupy the centre of the cell within the nuclear network. Later, an inflammatory reaction converts the xenomas to granulomas.

We have studied developing and mature (sporefilled) xenomas of $M$. vivaresi in T. bubalis. Active and spore-filled xenomas were found in liver, whereas all xenomas discovered in muscle were spore-filled and in an advanced stage of destruction. Analyses of its $16 \mathrm{~S}$ rDNA (GenBank Accession Number AJ2529520) placed it close to Spraguea lophii (see Cheney et al. 2000) and in a clade with $M$. caulleryi and Tetramicra brevifilum also close to Spraguea sp. (see Lom and Nilsen 2003). Here we present data on the organisation of young xenomas and on the host reaction which eventually destroys the infection.

\section{MATERIALS AND METHODS}

Twenty live T. bubalis collected from Portland Harbour, Weymouth, Dorset, UK $\left(50^{\circ} 35^{\prime} 02^{\prime \prime} \mathrm{N}, 02^{\circ} 26^{\prime} 47^{\prime}\right.$ 'W), were terminally anaesthetized by immersion in MS222 (Sandoz) in seawater. On dissection of the fish, the xenomas in liver and skeletal muscle were excised from surrounding tissue as cleanly as possible and fixed in $2.5 \%$ glutaraldehyde in phosphate buffer ( $\mathrm{pH}$ 7.2).

The cysts were post-fixed in osmium tetroxide in the same buffer, washed several times in buffer, dehydrated in graded ethanol, cleared in propylene oxide and embedded in Agar 100 resin (Agar Scientific). Semithin $(1.0 \mu \mathrm{m})$ sections were stained with toluidine blue and ultrathin sections with uranyl acetate and lead citrate. For electron microscopy, sections were viewed with an AEI EM801 or Philips CM10 electron microscope.

This paper was presented at the NATO Advanced Research Workshop "Emergent Pathogens in the 21st Century: First United Workshop on Microsporidia from Invertebrate and Vertebrate Hosts", held in České Budějovice, Czech Republic, July 12-15, 2004. 


\section{RESULTS}

Light microscopy. Xenomas of Microgemma vivaresi were numerous in both liver and muscle but, as the infections were encountered by chance during examinations for myxozoans, the prevalence of the microsporidia was not estimated and it is not known whether other organs were infected. The nature of the parasitized cells could not be determined with certainty but were thought to be parenchyma cells in liver and connective tissue cells rather than myocytes in muscle.

Xenomas in muscle were spindle-shaped, those collected measured up to $1.5 \times 0.35 \mathrm{~mm}$, lying between muscle bundles. The surface was undulating, probably having contracted on fixation and was surrounded by a wall of hyaline appearance with branching incursions deep into the parasitic mass (Fig. 1). In liver, xenomas were spherical, measuring up to $0.2 \mathrm{~mm}$ in diameter (Fig. 2). Some had a wall of hyaline appearance with incursions penetrating right to the centre of the xenoma, while others were thin-walled.

Electron microscopy. Unencapsulated xenomas in liver were bounded by a simple plasma membrane without formation of microvilli (Fig. 3). Infected cells either abutted on adjacent cells or were slightly detached from them. In the earliest stages of xenoma formation parasites were absent from the outer cell layer. Passing inwards from the plasma membrane was a region with abundant small vesicles, a region with typical cell organelles, including mitochondria and diffuse cisternae of rough endoplasmic reticulum (rer), then stacked rer closely associated with irregular nuclear profiles. Many nuclear profiles were elongate and narrow, branching and anastomosing in one plane, so that the branches appeared to enclose areas of cytoplasm. Other nuclear profiles were shorter and wider and tended to be rounded on the face towards the centre of the cell and to form branched arms towards the cell periphery. Rer stacks were located in almost every space between the arms (Fig. 4). Although many nuclear profiles appeared separated, narrow extensions between them (Fig. 3) suggested that the profiles were linked out of the plane of section. All indications are that the host cell nucleus remains entire but, in the form of a continuous network, separates the non-parasitized outer zone from the centre of the cell full of intermingled merogonic and sporogonic stages. Nucleic acids were distributed in each nuclear profile as a beaded network that also formed a lining to the envelope. The wider profiles exhibited one or more nucleoli.
Xenomas probably continue to grow until the fragile plasma membrane is breached. The arrival of host neutrophil-like cells and macrophages (Fig. 5) signals the demise of the host cell and the removal of all stages of the parasite. As degeneration of the host cell ensues, the nuclear network breaks down, the remaining nuclear profiles become pycnotic, the cytoplasm becomes diffuse, the cell organelles degenerate and the parasites extend into the periphery of the cell. Fibroblasts secreting collagen fibres accumulate in layers around the stricken cell, forming a dense wall within which spores and pre-spore stages are engulfed by macrophages (Figs. 5-8). Reactive cells, possibly proliferating macrophages, accumulate within the fibroblast sheath and penetrate deeply into the cell cytoplasm. The fibroblasts and the proliferating cells are the constituents of the hyaline material seen by light microscopy in the degenerating xenomas. Ingestion of numerous spores by the macrophages gives a superficial impression of multisporous sporogony in sporophorous vesicles (Fig. 7), in contrast to the separate distribution of spores in the intact xenomas (Fig. 4). Spores are digested in the macrophages first by thinning of the wall, then by removal of the contents (Fig. 8). In muscle only encapsulated xenomas packed with phagocytized spores were found (Fig. 9). Between the fibroblast sheath and the intact striated muscle was a layer of variable thickness composed mainly of myofibrils released from degenerate myocytes. The layers of fibroblasts and the dense accumulation of inner cells penetrating the spore mass were exactly as found in the degenerating liver xenomas. Ultimate granuloma formation and complete disappearance of the parasites was not observed.

\section{DISCUSSION}

Tissue reactions of fish to microsporidian infections have been the subjects of several investigations, which have shown that the basic response is similar but the outcome may be different. Dyková and Lom (1980) evaluated host reactions to nineteen species belonging to the genera Glugea, Spraguea, Ichthyosporidium, Pleistophora and the collective genus Microsporidium. They distinguished between reactions to xenomas, leading to elimination of parasites and granuloma formation, and reactions to diffuse infections that were not contained but spread to other sites (e.g. Pleistophora). Matthews and Matthews (1980) described xenomas induced by Tetramicra brevifilum in connective tissue between muscle bundles of turbot, Scophthalmus maximus.

Figs. 1-3. Microgemma vivaresi in Taurulus bubalis. Fig. 1. Light micrograph montage of a xenoma in skeletal muscle: the outer wavy surface is enclosed by fibroblasts forming a multi-layered sheath separating the cell from muscles (m). Groups of spores ingested by phagocytes are visible at the periphery (arrow). Strands (arrowhead) penetrating the spore mass are probably a mixture of fibroblasts and phagocytes. Fig. 2. Light micrograph of adjacent xenomas in liver showing weakly reactive host response (A) and productive response (B). In B phagocytized spores appear grouped rather than evenly distributed. L - normal liver cells. Fig. 3. Electron micrograph of the periphery of adjacent intact xenomas showing the simple plasma membrane (arrow), layer of small vesicles (v), layer with mitochondria (mi), stack of endoplasmic reticulum (er), nuclear profiles (n), probably connected by narrow isthmuses (arrowhead) and zone of parasitized cytoplasm (z). Scale bars: Fig. $1=0.15 \mathrm{~mm}$; Fig. $2=45 \mu \mathrm{m}$; Fig. $3=4.6$ $\mu \mathrm{m}$. 


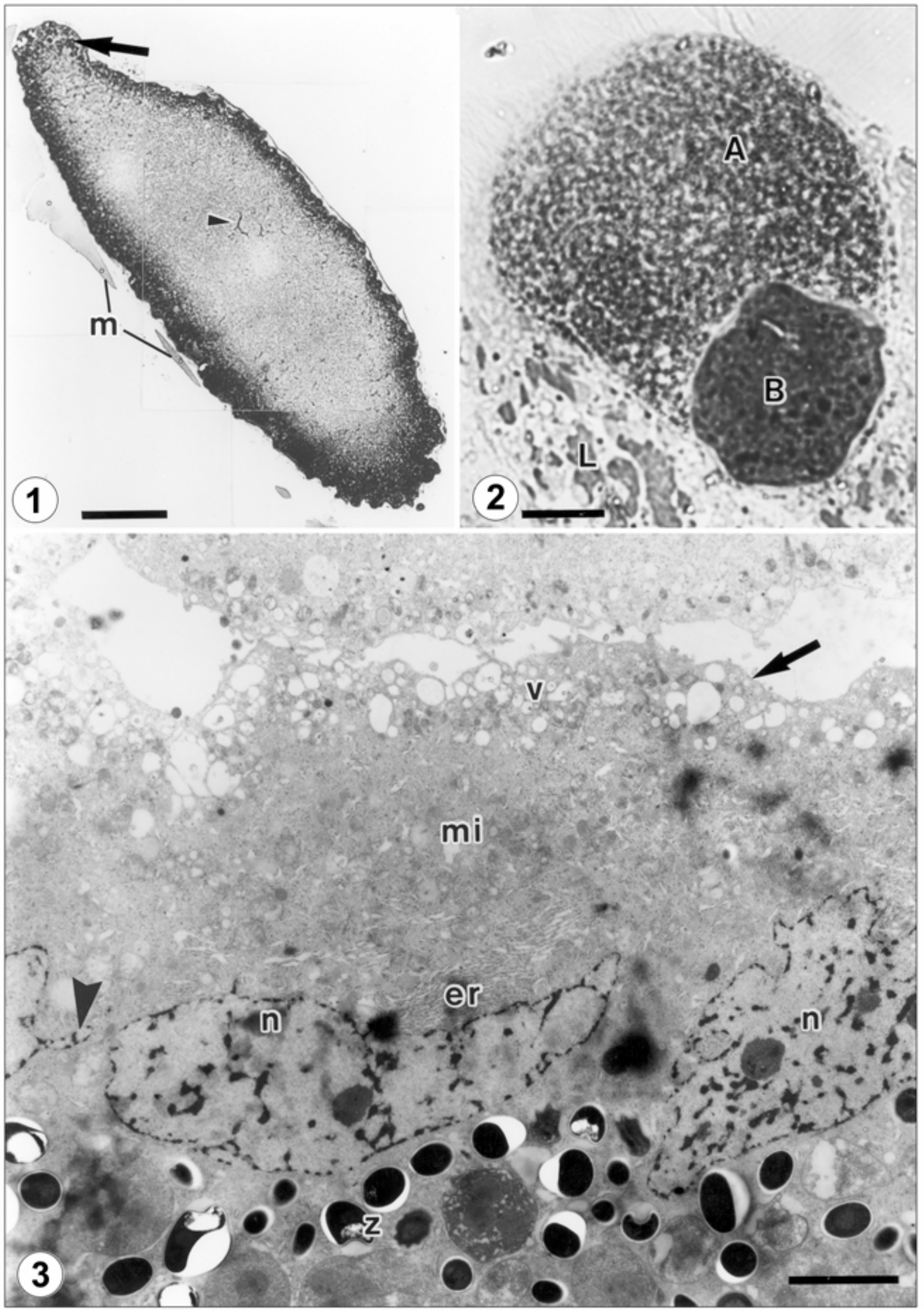




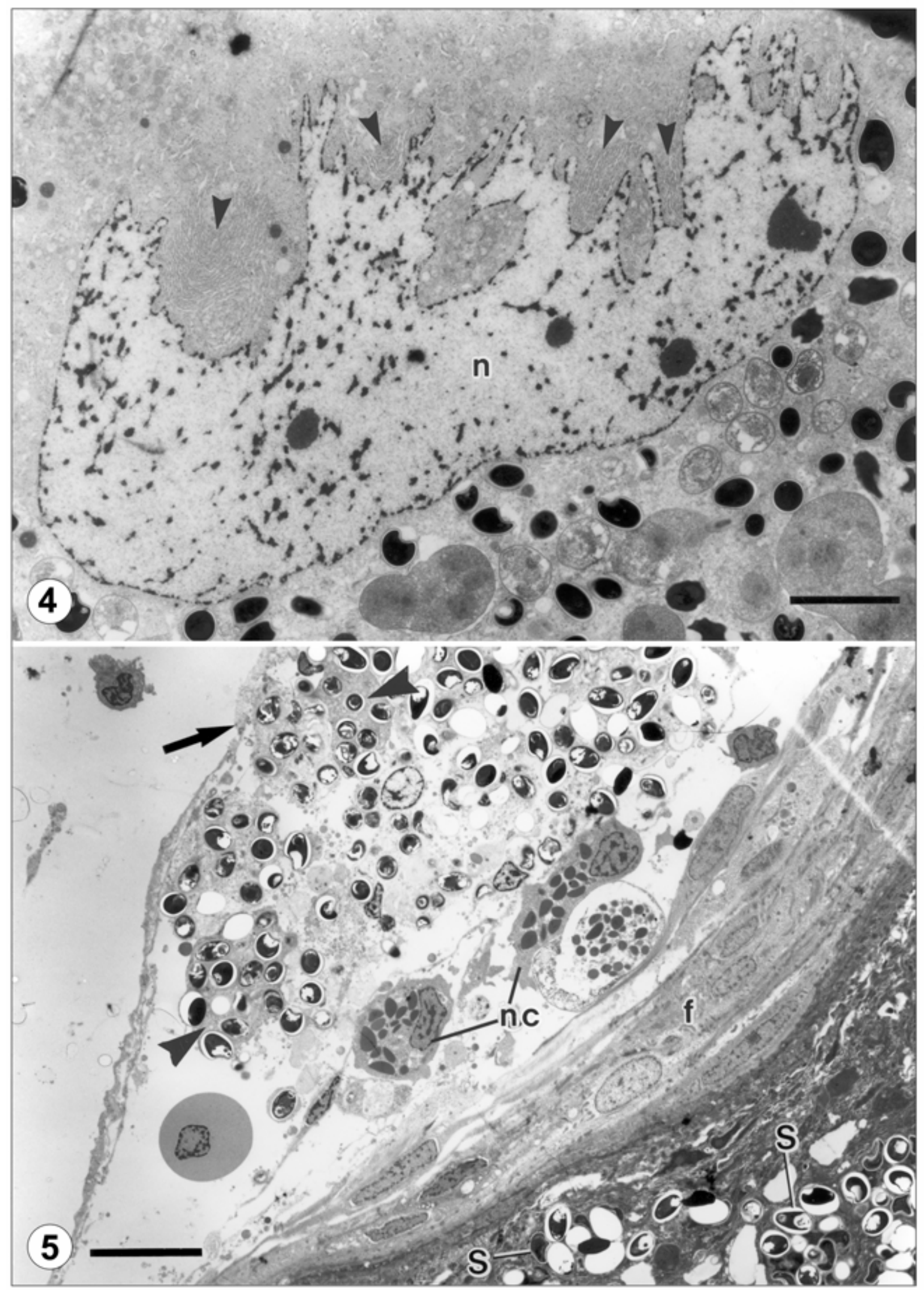




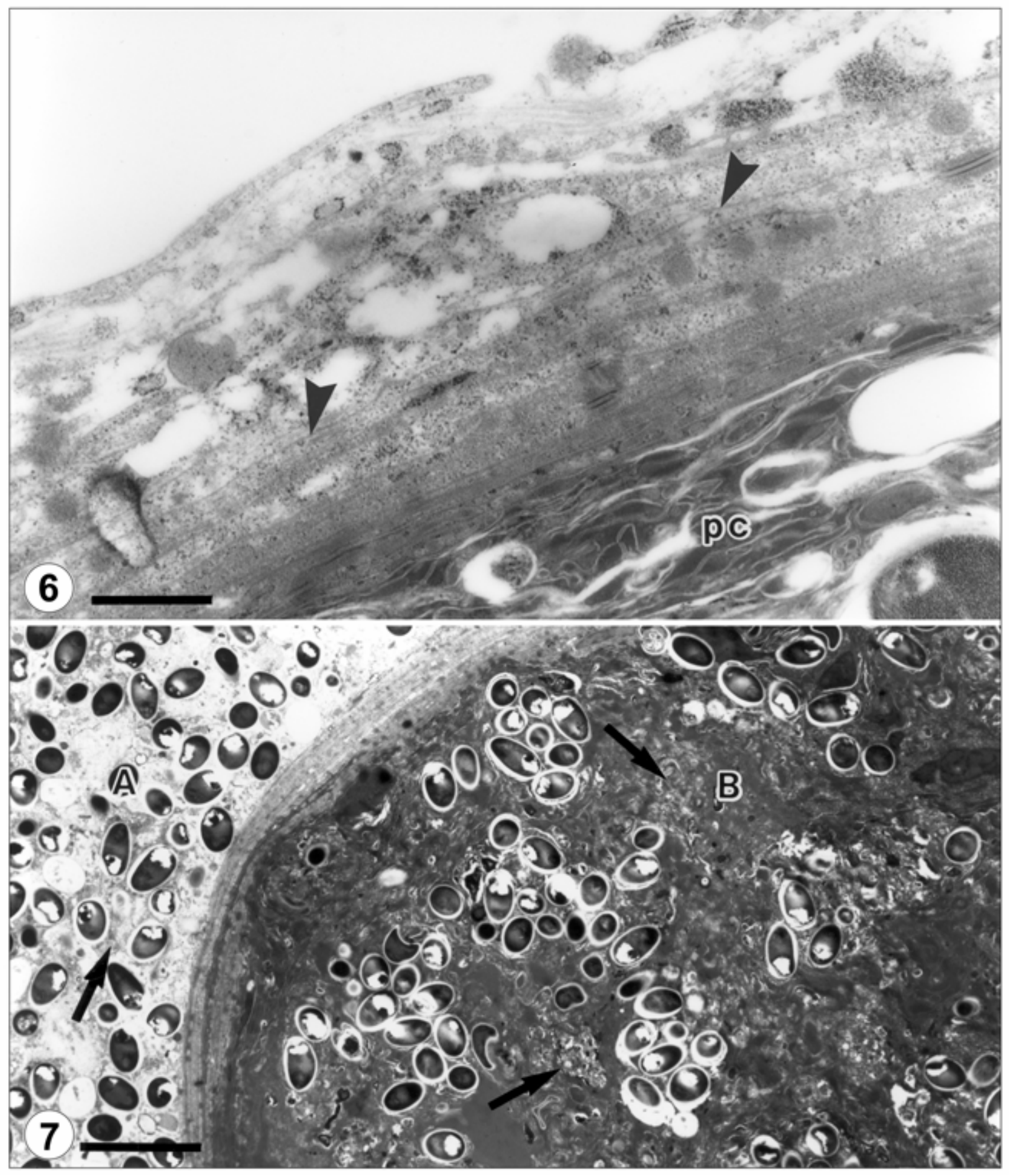

Figs. 4-7. Microgemma vivaresi in Taurulus bubalis. Fig. 4. Profile of xenoma nucleus (n), showing stacks of endoplasmic reticulum (arrowheads) in most of the crevices between irregular nuclear branches into the non-parasitized peripheral cytoplasm. The microsporidia occupy the cytoplasm internal to the nucleus. Fig. 5. Adjacent xenomas. Lower right shows a productive host reaction with enveloping layers of fibroblasts (f) and groups of spores (S) ingested by phagocytes. Upper left shows an early response with invading neutrophil-like cells $(\mathrm{nc})$ and mainly phagocytized spores (arrowheads) but lacking a strong fibroblast response on the plasma membrane (arrow). Fig. 6. Productive host response: fibroblasts depositing collagen fibrils (arrowheads), overlying proliferating cells $(\mathrm{pc})$, which are probably phagocytes. Fig. 7. Adjacent xenomas. A shows a weakly reactive response with some spores phagocytized (arrow) and others free; B shows a productive host reaction with groups of spores ingested by phagocytes, many being in the final stages of digestion (arrows). Scale bars: Fig. $4=6 \mu \mathrm{m}$; Fig. $5=8.2 \mu \mathrm{m}$; Fig. $6=0.9 \mu \mathrm{m}$; Fig. $7=6.2 \mu \mathrm{m}$; 


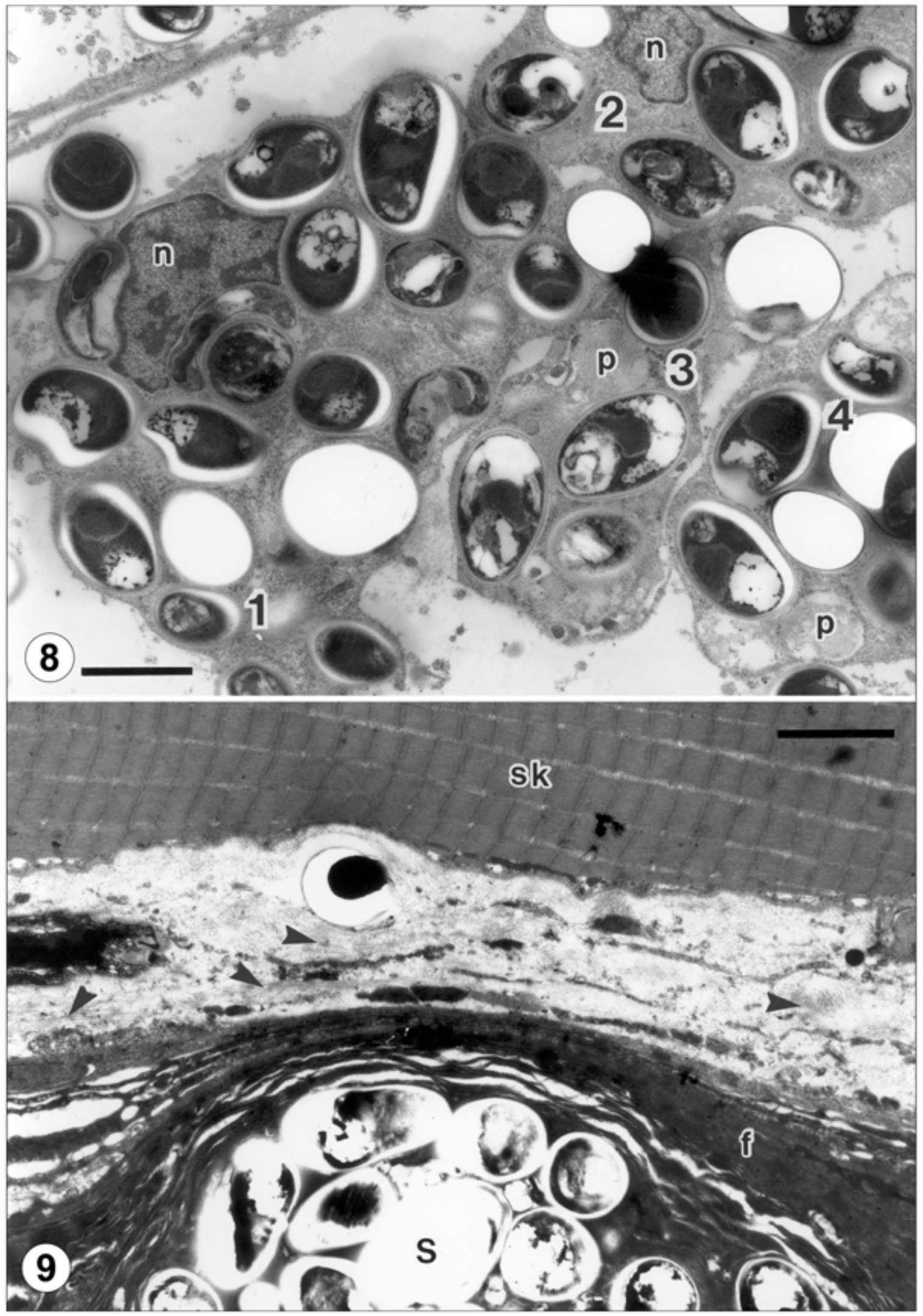

Figs. 8, 9. Microgemma vivaresi in Taurulus bubalis. Fig. 8. Macrophages (1-4) with ingested spores and pre-spore stages (p). $\mathrm{n}$ - macrophage nuclei. Fig. 9. Phagocytized spores (S) within multiple layers of fibroblasts (f) separated from skeletal muscle (sk) by a zone with myofibrils (arrowheads) from broken down myocytes. Scale bars: Fig. $8=2.0 \mu \mathrm{m}$; Fig. $9=2.2 \mu \mathrm{m}$. 
These had a simple plasma membrane but formed branching and anastomosing cytoplasmic processes emanating from the surface, which could interlock with those of adjacent infected cells and form composite cysts. Release of spores into surrounding connective tissue was followed by deposition of collagen, infiltration of leucocytes, uptake of spores by macrophages and local necrosis. The reaction appeared to be directed towards removal of diffused stages rather than containment within the xenoma.

Further light is thrown on the inflammatory events by the studies of early and late development of xenomas caused by Loma salmonae in rainbow trout, Oncorhynchus mykiss (Rodríguez-Tovar et al. 2002, 2003). Infected cells were identified as blood cells, possibly retained in lamellar capillaries because of their enlargement, pillar cells of secondary lamellae and cells lying between the endothelium and basement membrane of lamellar arteries. A weak inflammatory response, not involving invasion of xenomas, was observed at four weeks post infection (p.i.) (Rodríguez-Tovar et al. 2002). In the later study (Rodríguez-Tovar et al. 2003) three types of xenoma were identified: rounded xenomas derived from pillar cells, flattened xenomas lying under the arterial endothelium, and irregular xenomas in connective tissue of the gill filament. Host reaction against the rounded xenomas was first observed at six weeks p.i. and involved only a fibroblast overlay. At seven weeks p.i., gaps were observed in the fibroblast layer, exposing the plasma membrane and the xenomas were invaded by phagocytes. It is possible that the plasma membrane had been slightly damaged out of the plane of section, exposing parasite antigens and initiating the phagocyte invasion. Some support for this is provided by the complete absence of inflammatory cells around the flattened and irregular xenomas at the same time p.i., indicating that the host still did not recognise these as foreign.

Glugea xenomas are supported, and presumably protected, by layer upon layer of cell coat alternately secreted and sloughed off from the parasitized cell (Weidner 1976, Canning et al. 1982). Although the xenomas of Microgemma vivaresi in Taurulus bubalis have a simple plasma membrane and no protective thickenings, the inflammatory response is similar to the reactions to Glugea spp. culminating in granuloma formation. Dyková and Lom (1980) proposed that growth of Glugea xenomas causes pressure atrophy of the surrounding cells and that this may elicit the first response. Thus, deposition of a connective tissue layer around the xenoma and fibroblast infiltration between the layers of surface coat would destroy the protective coat and allow phagocytes to enter the spore-laden cell. However, the extensive growth of the xenoma once it has entered into a symbiotic relationship with its parasites is testimony that the host does not recognise the cell as foreign. The small vesicles beneath the plasma membrane and the close association of rer stacks with the greatly enlarged nucleus and the multiple nucleoli are modifications for greater uptake of nutrients and increased protein synthesis for the continuing enlargement of the cell. It is unlikely that a host reaction would be initiated while the plasma membrane remained intact. Breaches in the plasma membrane may occur naturally once the cell has reached the limit of its growth or may be caused by mechanical disruption by pressure from surrounding tissue. Once this has occurred, parasite antigens will be exposed and stimulate the inflammatory response of phagocyte entry into the xenoma and fibroblast deposition around it.

Dyková and Lom (1980) classified the stages leading to destruction of xenomas as weakly reactive, as in early $M$. vivaresi xenomas (Fig. 2 A) giving way to a productive stage (Fig. 2 B) and finally to digestion of parasites and granuloma involution. In the case of $M$. vivaresi, there are no protective layers of surface coat on the xenoma and the first sign of host reaction is the entry of neutrophil-like cells and macrophages into the xenoma. This phase is followed by accumulation of fibroblasts and deposition of collagen to seal off the dying cell from surrounding tissue. Thereafter, proliferation and migration of fibroblasts and phagocytic cells deep into the xenoma leads to destruction and removal of parasites and presumably involution of the granuloma, although the final stage has not been observed. Leiro et al. (1999) described a similar mechanism for isolating and destroying liver cells infected with $M$. caulleryi in sand eels.

Dyková and Lom (1980) found secondary xenomas of Glugea anomala growing within the granulation tissue around a primary xenoma but were unable to determine whether they originated by spontaneous hatching of spores formed in the primary xenoma or after ingestion of spores by migratory cells. In any case they concluded that the secondary xenomas would remain (and presumably be destroyed) in the granuloma. They did not find secondary xenomas developing near intact xenomas. Rodríguez-Tovar et al. (2003) observed polar tubes extruded from spores of $L$. salmonae in rounded xenomas invaded by phagocytes. They proposed that this might be a mechanism for autoinfection, if nearby leucocytes could sustain infections if inoculated with sporoplasms via polar tubes. In at least one site in the liver of $T$. bubalis, xenomas of $M$. vivaresi of different ages were found adjacent to one another (Fig. 2). In this case either a sporoplasm had been transported through a discharged polar tube from within the older xenoma into a neighbouring susceptible cell or the two cells had been infected independently at different times by the chance entry of two sporoplasms germinated from separate spores, perhaps brought to the site by nearby blood vessels. In spite of the proximity of the two xenomas, the inflammatory response was at the productive stage in one and at the weakly reactive stage in the other, show- 
ing that the responses to the two xenomas were not simultaneous. This supports the concept that parasite antigen must be released from the xenoma before the host can react against one of its own cells.

It is interesting that the liver cells of $T$. bubalis infected with $M$. vivaresi can reach a diameter of at least $200 \mu \mathrm{m}$ without the need for support. This appears to be true of xenomas caused by the other described species of Microgemma (see Ralphs and Matthews 1986,
Amigó et al. 1996, Leiro et al. 1999) and Tetramicra brevifilum (see Matthews and Matthews 1980). This is in contrast to Glugea xenomas where initial support and protection is provided by the multiple layers of surface coat sloughed off and re-secreted by the host cell.

Acknowledgements. The authors are grateful to Drs. S.W. Feist and M. Longshaw for assistance in fish collection and laboratory facilities and to Trish Rowland for electron microscopy.

\section{REFERENCES}

AMIGÓ J.M., SALVADÓ H., GRACIA M.P., VIVARÈS C.P. 1996: Ultrastructure and development of Microsporidium ovoideum (Thélohan, 1895) Sprague, 1977, a microsporidian parasite of the red band fish (Cepola macrophthalma L.) - Redescription of the organism and reassignment to the genus Microgemma Ralphs \& Matthews, 1986. Eur. J. Protistol. 32: 532-538.

CANNING E.U., FEIST S.W., LONGSHAW M., OKAMURA B., ANDERSON C.L., TSUEY TSE M., CURRY A. 2005: Microgemma vivaresi $\mathrm{n}$. sp. (Microsporidia, Tetramicridae), infecting liver and skeletal muscle of sea scorpions, Taurulus bubalis (Euphrasen, 1786) (Osteichthyes, Cottidae), an inshore, littoral fish. J. Eukaryot. Microbiol. 52: 123-131.

CANNING E.U., LOM J., NICOLAS J.P. 1982: Genus Glugea Thélohan, 1891: (Phylum Microspora): redescription of the type species Glugea anomala (Moniez, 1887) and recognition of its sporogonic development within sporophorous vesicles (pansporoblastic membranes). Protistologica 18: 193-210.

CHENEY S.A., LAFRANCHI-TRISTEM N.J., CANNING E.U. 2000: Phylogenetic relationships of Pleistophoralike microsporidia based on small subunit ribosomal DNA sequences and implications for the source of Trachipleistophora hominis infections. J. Eukaryot. Microbiol. 47: 280-287.

DYKOVÁ I., LOM J. 1980: Tissue reactions to microsporidian infections in fish. J. Fish Dis. 3: 265-283.

LEIRO J., PARAMÁ A., ORTEGA M., SANTAMARINA M.T., SANMARTÍN M.L. 1999: Redescription of Glugea caulleryi, a microsporidian parasite of the greater sand eel, Hyperoplus lanceolatus (Le Sauvage), (Teleostei: Ammodytidae), as Microgemma caulleryi comb. nov. J. Fish Dis. 22: $101-110$.

LOM J., NILSEN F. 2003: Fish microsporidia: fine structural diversity and phylogeny. Int. J. Parasitol. 33: 107-127.

MATTHEWS R.A., MATTHEWS B.F. 1980: Cell and tissue reactions of turbot Scophthalmus maximus (L.) to Tetramicra brevifilum gen. n., sp. n. (Microspora). J. Fish Dis. 3: 495-515.

RALPHS J.R., MATTHEWS R.A. 1986: Hepatic microsporidiosis of juvenile grey mullet, Chelon labrosus (Risso), due to Microgemma hepaticus gen. nov. sp. nov. J. Fish Dis. 9: 225-242.

RODRÍGUEZ-TOVAR L.E., WRIGHT G.M., WADOWSKA D.W., SPEARE D.J., MARKHAM D.J.F. 2002: Ultrastructural study of the early development and localization of Loma salmonae in the gills of experimentally infected rainbow trout. J. Parasitol. 88: 244-253.

RODRÍGUEZ-TOVAR L.E., WRIGHT G.M., WADOWSKA D.W., SPEARE D.J., MARKHAM D.J.F. 2003: Ultrastructural study of the late stages of Loma salmonae development in the gills of experimentally infected rainbow trout. J. Parasitol. 89: 464-474.

VAN DEN BERGHE L. 1940: Glugea caulleryi nom. n. for Glugea microspora Van den Berghe, 1939, preoccupied. J. Parasitol. 26: 238.

WEIDNER E. 1976: Ultrastructure of the peripheral zone of a Glugea-induced xenoma. J. Protozool. 23: 234-238. 